\title{
Necrológica
}

\section{Julián Ortega Carnicer: in memoriam}

Dichoso el varón que medita sobre la sabiduría, y atiende a la inteligencia; que aplica su espíritu a los caminos de ella y considera sus senderos, sale tras ella como un explorador y en sus entradas pónese en acecho

\section{Eclesiástico; 14, 20-21}

Hace poco que ha fallecido Julián Ortega. La noticia no por esperada se ha hecho menos dolorosa.

Para los lectores de esta revista su nombre no resultará desconocido, pues durante muchos años sus artículos en estas páginas y en otras publicaciones de ámbito internacional han aparecido con una frecuencia poco común, incluso cuando sabía ya que su vida tenía un plazo corto, haciendo en ellos siempre evidente una perspicacia clínica inusual.

El Dr. Ortega fue residente e inició su labor como intensivista en el Hospital 12 de Octubre y, muy joven todavía, volvió a su tierra manchega al ganar por oposición la plaza de Jefe de Servicio del Hospital Provincial de Ciudad Real, asumiendo posteriormente la dirección del Servicio de Medicina Intensiva del Complejo Hospitalario de esa ciudad.

Esta labor de dirección de servicio no impidió nunca que atendiera a sus pacientes ni que tuviera un conocimiento diario y preciso del resto de enfermos ingresados en la unidad.

Prácticamente todas las tardes acudía a su despacho del hospital para proseguir con su formación, preparar sus publicaciones e interesarse por algún paciente de especial dificultad diagnóstica o de manejo.

Al rigor directivo y asistencial añadió su ansia científica y el interés por la innovación. Fue pionero en la organización de sistemas de emergencia extrahospitalaria en España, y Ciudad Real fue la primera provincia de Europa en que se realizara fibrinólisis extrahospitalaria; participó en ensayos clínicos internacionales y en mesas de consenso y fue corrector de revistas internacionales, así como director de múltiples monografías.

Solamente en los últimos tiempos la avanzada enfermedad frenó, que no impidió, mantener esta incesante actividad, conservando activo e intacto el interés por la marcha de su servicio.

Evidentemente esa actitud y su fuerte personalidad no pudieron menos que imprimir carácter en el modo de trabajo del personal sanitario a su cargo.

En su mente siempre tuvo como norte hacer de un pequeño servicio, de un pequeño hospital, de una pequeña y hermosa capital de provincia, un punto de referencia de calidad asistencial y de consideración profesional en el entorno sanitario de la región, así como en el ámbito de la Medicina Intensiva de nuestro país.

Su esfuerzo, desarrollado al final de su vida activa en el marco del nuevo Hospital General de Ciudad Real, contribuyó, como creo se deberá reconocer, a la mejora de la atención sanitaria en Castilla-La Mancha.

Descanse en paz. 